\title{
Reforming the Regulation on Spirit Drinks - an Example of Better Regulation?
}

\author{
Oliver BARTLETT*
}

\section{INTRODUCTION}

The EU institutions are currently revising the Spirit Drinks Regulation (EC) 110/ $2008,{ }^{1}$ the primary piece of legislation that regulates the production of spirit drinks within Europe. The Commission published its proposal in December 2016, ${ }^{2}$ and the European Parliament (EP) adopted its report on the proposal in January $2018 .^{3}$ In March 2018 the EP approved the opening of trilogue negotiations, to continue the legislative process.

This reform itself is mostly unremarkable, its main objective being to align the existing Regulation with the TFEU, supposedly without changing the scope of protection already offered by the existing Regulation. The most interesting change made is the introduction of a new procedure for the management and registration of geographical indications of spirit drinks. The Commission's proposal has been made in light of “the Member States' and stakeholders' expectations of regulatory simplification and ... the guiding principles of better regulation". ${ }^{4}$ This short report will examine whether the Juncker Commission's drive for "better regulation" has been realised in this particular corner of the alcohol policy field. It will briefly outline the purpose of the "better regulation" agenda, and will then offer comment upon whether certain salient aspects of the Commission's proposal represent "better regulation".

\section{The "BEtTER REgUlation” AGENDA}

The current Juncker Commission was elected on the political mandate of "better regulation", 5 which according to the recently reviewed Commission guidelines on the

* University of Liverpool, ojb@liverpool.ac.uk.

1 Regulation (EC) No 110/2008 of the European Parliament and of the Council of 15 January 2008 on the definition, description, presentation, labelling and the protection of geographical indications of spirit drinks, OJ L 39/16, 13.2.2008.

2 Proposal for a Regulation of the Parliament and Council on the definition, presentation and labelling of spirit drinks, the use of the names of spirit drinks in the presentation and labelling of other foodstuffs and the protection of geographical indications for spirit drinks, $\operatorname{COM}(2016) 750$ final, 2.

3 Report of the European Parliament on the proposal for a regulation on spirit drinks, A8-0021/2018, 2.2.2018.

4 Commission proposal, supra, note 2.

5 Jean-Claude Juncker, "Political Guidelines for the next European Commission" (Strasbourg, 15 July 2014). 
matter means "designing EU policies and laws so that they achieve their objectives at minimum cost". ${ }^{6}$ It is a "way of working to ensure that political decisions are prepared in an open, transparent manner, informed by the best available evidence and backed by the comprehensive involvement of stakeholders". 7 An important mechanism that the Commission utilises to pursue its better regulation agenda ${ }^{8}$ is the Regulatory Fitness and Performance Programme (REFIT), the objective of which is to ensure that EU laws are delivering their expected benefits to citizens, are cost-effective, and are not producing unnecessary red-tape. ${ }^{9}$ Several further initiatives have been pursued by the Commission to support the better regulation agenda, including the conclusion of a new Interinstitutional Agreement (IIA) on Better Law-Making, ${ }^{10}$ and the establishment of a Task Force on Subsidiarity, Proportionality and "Doing Less More Efficiently". ${ }^{11}$

According to the Commission, its "track record so far shows that the ... commitment to better regulation is not just lip service. It is a fact". ${ }^{12}$ The ever amassing literature on the subject, however, tends not to agree-although the Commission has certainly committed to the task of cutting red-tape, the impact of the newly revitalised better regulation agenda has been a matter of suspicion. ${ }^{13}$ In particular, concerns have been voiced that the better regulation agenda may even undermine established legal protection in social or environmental policy fields, ${ }^{14}$ despite the insistence of the Commission that "better regulation is not about 'more' or 'less' EU legislation; nor is it about deregulating or deprioritising certain policy areas or compromising the values that we hold dear: social and environmental protection, and fundamental rights including health - to name just a few examples". 15

The proposal for a new Spirit Drinks Regulation is not formally part of the REFIT programme, however it is nonetheless an opportunity to deploy the principles of better regulation. This report turns now to consider salient changes made by the Commission's proposal and whether or not they constitute examples of better regulation.

\footnotetext{
6 Commission Staff Working Document, “Better Regulation Guidelines”, SWD (2017) 350 (Brussels, 7 July 2017).

7 ibid.

8 ibid.

9 Commission Communication, "EU Regulatory Fitness", COM (2012).

10 Interinstitutional Agreement of 13 April 2016 on Better Law-Making, OJ L 123/1, 12.5.2016.

11 Decision of the President of the European Commission on the Establishment of Task Force on Subsidiarity, Proportionality and "Doing Less More Efficiently", C (2017) 7810.

12 Commission Communication, "Better Regulation: Delivering better results for a stronger Union", COM (2016) 615 final, 8 .

13 See, for example, C Radaelli and L Schrefler, "Contribution to the Better Regulation Debate" (2015) 6(3) EJRR 357; R Meads and L Allio, "Paving the Way to an Improved, Modern Management of Risk: The new European Commission's Better Regulation Strategy" (2015) 6(4) EJRR 649; A Brunea and R Ibenskas, "Unveiling patterns of contestation over better Regulation reforms in the European Union" (2017) 95 Pub Admin 589; M Pedersen, "Qui Exanimis Nascitur? Can the REFIT Programme in the European Union deliver better regulation" (2017) 8(2) EJRR 387. 14 See, for example, A Aragao et al, "The true face of Better Regulation regarding environmental policy" (University of Oslo Faculty of Law Legal Studies Research Paper Series No 2015-10); U Pachl, "Repercussions of the European Commission's Better Regulation Agenda on Consumer Interests and Policy" (2015) 6(3) EJRR 375; A Renda, "How can Sustainable Development Goals be 'mainstreamed' in the EU's Better Regulation Agenda?" (CEPS Policy Insights No 2017/12).

15 Commission Communication, "Better regulation for better results - An EU agenda", COM (2015) 215 final, 4.
} 


\section{Better Regulation within the Commission's PRoposals?}

The main thrust of the Commission's proposal is - aside from aligning the Regulation with the provisions of the Lisbon Treaty on delegated powers - to reform the way in which geographical indications of spirit drinks are registered and protected. In particular, in addition to introducing streamlined procedures for managing the registration process, the proposal replaces Annex III of the Regulation with a "publicly accessible updated electronic register of geographical indications of spirit drinks" 16 that the Commission will establish through implementing acts. The rationale behind this change is to adopt a model for managing protected designations of origin that has already been successfully implemented for agricultural products and foodstuffs in Regulation 1151/2012, ${ }^{17}$ and which would "simplify the registration procedures and ... ensure that information for food business operators and consumers is electronically available". ${ }^{18}$ This is a change approved of by the EP - in particular, the rapporteur appointed by the Committee on International Trade (the INTA Committee's opinion was sought by the Environment, Public Health and Food Safety Committee, who are primarily responsible for producing the EP's report on the proposal), commented that the introduction of an electronic register of geographic indications for spirit drinks is "undoubtedly a commendable objective of the proposal. It could well prove to be an innovative, dynamic, transparent and more easily accessible tool". ${ }^{19}$ Indeed, it seems that this reform is made in the spirit of better regulation - the Commission's 2017 Guidelines repeatedly advocate for "simplifying existing interventions or improving efficiency of existing interventions", as well as the possibility for deploying "new technological developments and ICTs". ${ }^{20}$ Transferring the list of protected geographic indications from an Annex to an online database seems to fit well with the guidance that initiatives should be "digital and internet ready and operate effectively both in the digital and physical worlds". 21

Other aspects of the Commission's proposal, however, arguably do not support the better regulation agenda. The most obvious to emerge from the EP's report is the alignment with Articles 290 and 291 TFEU on delegated powers. The original proposal conferred power on the Commission to adopt implementing acts in relation to labelling and geographic indications, including the new electronic register discussed above. The EP's report points out, however, that if the Commission were to use implementing acts, the powers and rights of oversight held by the EP in the existing procedure for registering and managing spirit drink geographic indications would have been weakened. In the existing Regulation, the adoption of implementing acts by the Commission was subject to Council Decision $1999 / 468,{ }^{22}$ which afforded the EP

16 Commission proposal, supra, note 2, Art 30.

17 Commission Proposal, supra, note 2, recital 19. See also Regulation (EU) No 1151/2012 of the European Parliament and of the Council of 21 November 2012 on quality schemes for agricultural products and foodstuffs, OJ L 343/1, 14.12.2012.

18 Commission Proposal, supra, note 2, recital 19.

19 Report of the European Parliament on the proposal for a regulation on spirit drinks, A8-0021/2018, 2.2.2018, 90.

20 Better Regulation Guidelines, supra, note 6, 21.

21 ibid.

22 Council Decision of 28 June 1999 laying down the procedure for the exercise of implementing powers conferred on the Commission, OJ L 184/23, 17.7.1999. 
extensive rights to scrutinise and control the adoption of implementing acts. The current proposal states that the adoption of implementing acts shall be in accordance with Regulation 182/2011, ${ }^{23}$ which affords the EP more limited advisory powers. Since the Commission's proposal makes no reference to the previous powers of Decision 1999/ 468 (preserved by Regulation 182/2011 where they are referred to in existing EU legislation), the proposal appears to effectively remove the ability of the EP to amend or veto the content of the implementing acts that would establish the new geographic indication protection system.

Thus, as the ENVI Committee rapporteur points out, "it is important that the prerogatives Parliament already had under legislation in force be maintained in any alignment process", ${ }^{24}$ particularly in relation to future changes to the proposed electronic register. Accordingly, the use of delegated acts instead of implementing acts is proposed, as delegated acts under Article 290 TFEU may only be adopted by the Commission within the strict parameters set by the delegating EU legislation, and may be revoked or changed at the insistence of the EP or Council. The rapporteur for the INTA Committee also emphasised the need for delegated acts, since they would "relate to key provisions of the Regulation, necessitating wide cooperation and an unhindered exchange of information between Member States, Parliament and the Commission, so as to respond more effectively to the needs and interests of the sector". 25

The guaranteed input of the EP into the establishment of the new regime would therefore seem an essential element to its future success, and furthermore seems to support the idea of better regulation. The Commission acknowledges as much by referencing the IIA on Better Law-Making in recital 24 to its proposal, and the need to "ensure equal participation in the preparation of delegated acts",26 within the proposed new regulation. It seems, though, that the Commission did not initially consider this necessary for all aspects of the proposed spirit regulation regime - the decision to use implementing acts for arguably the most important aspects of the Regulation appears to be at odds with the IIA, to the extent that Article 26 of the IIA states that "it is the competence of the legislator to decide whether and to what extent to use delegated or implementing acts", ${ }^{27}$ and Article 2 states that the EU institutions commit to "promote the utmost transparency of the legislative process". Thus, the initial decision to use implementing acts does not appear to fully support the better regulation commitments.

Another aspect of the proposal worth highlighting is the Commission's decision to forgo the opportunity to conduct an impact assessment. The Better Regulation Guidelines indicate that the impact assessment process "is about gathering and analysing evidence to support policymaking", and "analyses the advantages and disadvantages of available solutions". ${ }^{28}$ It "promotes more informed decision-making

\footnotetext{
23 Regulation (EU) 182/2011 of the European Parliament and Council of 16 February 2011 laying down the rules and general principles concerning mechanisms for control by Member States of the Commission's exercise of implementing powers, OJ L 55/13, 28.2.2011.

24 European Parliament Report, supra, note 3, 88.

25 ibid, 90.

26 Commission proposal, supra, note 2, recital 24.

27 Emphasis added.

28 Better Regulation Guidelines, supra, note 6, 15.
} 
and contributes to better regulation", and is required for any Commission initiatives that "that are likely to have significant economic, environmental or social impacts". ${ }^{29}$ The IIA furthermore indicates that impact assessments should, "cover the existence, scale and consequences of a problem" and "map out alternative solutions and, where possible, potential short and long-term costs and benefits". ${ }^{30}$ Impact assessment should be carried out when proposals have "significant" economic, environmental or social impacts, and considering that the Commission did not propose to substantively change the scope of protection offered by the existing Regulation, the decision not to conduct an impact assessment therefore appears unproblematic.

However, as some stakeholder responses suggest, the Commission's proposal does in fact change certain aspects of the protection offered to registered geographical indications. In particular, Spirits Europe pointed out that the proposal removed the ability to register a new geographical indication in two languages. ${ }^{31}$ This, Spirits Europe claim, will threaten $€ 1$.2bn worth of exports, where laws in export markets require that a geographical indication be translated before a spirit can be sold. If this claim is accurate, the economic impact of this part of the Commission's proposal could readily be interpreted as "significant", in which case an impact assessment would have been warranted under the Better Regulation Guidelines. If the economic impact is more modest, then at the very least it is difficult to reconcile the fact that some of the proposed changes are substantive with the overview of said changes given in the explanatory statement accompanying the proposal. It would seem that forgoing an impact assessment here should not have been an automatic conclusion. Although Tool \#9 of the Better Regulation Toolbox ${ }^{32}$ states that legal alignments (which this proposal is) do not have to be accompanied by an impact assessment a priori, due to lack of policy alternative or significant direct impacts, the contentions of certain stakeholders suggest that the proposals may have significant impacts. ${ }^{33}$ Tool \#9 also states that the need for an impact assessment should be assessed in the case of revisions to existing legal acts (which this proposal also is), and furthermore that micro-level impacts can be considered just as "significant" as macro-level impacts. Since the Toolbox ultimately suggests that "an IA should be carried out only when it is useful", 34 and given that the Commission's proposals contain changes that may or may not have significant substantive impacts, an impact assessment might well have been useful for this proposal in the spirit of better regulation, to establish the exact extent and consequences of the innovations introduced.

\footnotetext{
29 ibid

30 Interinstitutional Agreement, supra, note 10, para. 12.

31 See the response to the Commission proposal from Spirits Europe: "Securing the Right Legal Framework for European Spirits: Updating Regulation 110/2008" available online at < spirits.eu/upload/files/COM001-2017\% 20Initial\%20views\%20on\%20Reg\%20110.pdf > (last accessed 20 April 2018).

32 The Toolbox provides more detailed advice on how to apply the principles of better regulation, and is available at $<$ ec.europa.eu/info/better-regulation-toolbox_en > (last accessed 20 April 2018)

33 Available online at <ec.europa.eu/info/sites/info/files/file_import/better-regulation-toolbox-9_en_0.pdf > (last accessed 20 April 2018)

34 ibid.
} 


\section{Concluding Remarks}

At the time of writing the Commission's proposal has moved on to trilogue negotiations, and the 590 amendments tabled by the EP will now be discussed by the EP, Council and Commission. This reform to the Spirit Drinks Regulation was never intended to be groundbreaking, however the scrutiny conducted by the EP, as well as various stakeholders and national parliaments, has revealed some salient concerns. A seemingly straightforward procedure to align the existing regulation with the TFEU has raised the issue of whether the EP's rights of scrutiny over the implementation of the spirit drinks regulatory regime are being eroded. The Reasoned Opinion sent by the Italian Senate even suggests in this regard that the Commission has not acted in compliance with the principles of subsidiarity and proportionality, on the basis that its proposal "introduces innovative elements into the existing legal framework on the protection of geographical indications of spirit drinks and provides for powers to be delegated to the European Commission which lie outside the scope of Article 290 TFEU". ${ }^{35}$ If one questions whether the proposal is in fact altering the scope of protection offered by the existing Regulation, one must then ask whether an impact assessment should have been performed to ascertain exactly what effect the changes might have. It appears that, despite the entirely welcome efforts of the Commission to bring the regulation of spirit drinks into the digital age, and in line with the regimes applicable to other agricultural and food products, some parts of its legislative proposal arguably do not represent "better regulation".

\footnotetext{
35 The official reasoned opinion is available at <www.connefof.europarl.europa.eu/connefof/app/exp/COM(2016) $0750>$ and a courtesy English translation is available at <www.ipex.eu/IPEXL-WEB/scrutiny/COM20160750/itsen. do $>$ (both last accessed 20 April 2018).
} 